\title{
Social Isolation - a Prerequisite for Forced and Intensive Development of Media Literacy and Digital Education of Society
}

Zhivko Rachev

Faculty of educational studies and the arts,

Sofia University “Kliment Ohridski," Bulgaria

\begin{abstract}
Социалната изолация - предпоставка за принудително и интензивно развитие на медийна грамотност и дигитално образование на обществото
\end{abstract}

\author{
Живко Рачев \\ Факултет по науки за образованието и изкуствата \\ Софийски университет „ Св. Климент Охридски”, България
}

\begin{abstract}
Author Note
Zhivko Rachev (D) https://orcid.org/0000-0001-7645-3901

The author has no conflict of interest to disclose.

Correspondence concerning this article should be addressed to Zhivko Rachev,
\end{abstract} Faculty of educational studies and arts, Sofia University „Kl. Ohridski““, 69A Shipchenski prohod Str. Email: Jiro1@abv.bg

\section{Бележки за автора}

Живко Рачев (Dttps://orcid.org/0000-0001-7645-3901

Авторьт няма конфликт на интереси.

Кореспонденцията, свързана с тази статия, може да се адресира до Живко Рачев Факултет по науки за образовението и изкуствата, Софийски университет „Св.Св.

Климент Охридски, ул. „Шипченски проход“69 A. Email: Jiro1@abv.bg 


\begin{abstract}
The paper analyzes the behavior of society in a crisis and social distance and the increased influence of the media. Data on the level of training of teachers, students and parents related to media and information literacy are presented. The degree of forced media literacy in crisis conditions is measured. Models and methods of distance and media learning within the European Union are compared. In conclusion, examples are given of media connections and media literacy in the absence of a social environment and live communication among children and students in the context of the COVID-19 pandemic.
\end{abstract}

Keywords: social isolation, media literacy, online learning models, COVID-19

\title{
Резюме
}

В статията се прави анализ на поведението на обществото в условия на криза и социална дистанцираност и засиленото влияние на медиите. Представят се данни за нивото на подготовка на учители, ученици и родители свързани с медийната и информационна грамотност. Измерва се степента на принудително придобитата медийна грамотност в условия на криза. Сравняват се моделите и методите на дистанционно и медийно обучение в границите на Европейския Съюз. В заключение се дават примери за връзки на медиите и медийната грамотност при липса на социална среда и жива комуникация при децата и учениците в условията на пандемията COVID-19.

Ключови думи: социална изолация, медийна грамотност, модели на онлайн обучение, COVID-19

\author{
ARTICLE INFO: \\ Original Article \\ Received: 20, 02.2021 \\ Revised: 02, 03.2021
}


Accepted: 20, 03.2021

\section{Социалната изолация - предпоставка за принудително и интензивно развитие на медийна грамотност и дигитално образование на обществото}

\section{Въведение}

Настоящата статия има за цел да акцентира върху съвкупността от всички реални комуникационни взаимодействия, които медиите осъществяват всекидневно с разнообразната по състав детска аудитория. Отговаря на въпроса какво трябва да се знае за медиите, за да може педагогическото взаимодействие и възпитанието да отговаря на изискванията и потребностите на модерното информационно общество. Посочва, че задача на медийната педагогика е конкретно да посочва на кои места интеракциите между медиите и хората - преди всичко децата, се намесват, като възпитават и образоват, обучават и съветват, ориентират и информират.

Насока на този анализ, не само според мен, е класическото определение на трите основни функции на медиите - да информират, забавляват и образоват като е потьрсен отговор на въпроса доколко тези роли са еднакво проучени и използвани в съвременното общество и най-вече по отношение работата с подрастващите. Въпреки преобладаването през 2020 година на дистанционното и електронно обучение в условията на пандемията COVID-19, определено считам, че е необходимо да поставим основен фокус върху третата и сякаш най-често пренебрегвана у нас функция на масмедиите, образователната - при това, в няколко аспекта. По правило новите характеристики на „новите медии“ се описват в термини като: създаване на мрежа, глобализация, мултимедия, умиране на разстояния, бързина, виртуалност, произволност, достьпност, интерактивност, тъй като те влияят върху качеството на комуникацията и ролите на комуникация в сравнение с утвърдените средства за масова информация бих искал да мисля, че ако човек говори за „новите медии“, наистина трябва да се говори за нови медии, а не само за медии с обогатена инфраструктура или диференцирана функционалност. По тази причина непрекъснато появяващите се нови форми на комуникация, осъществяваща се в интернет - електронна поща, чат, конферентна връзка, електронни страници, блогове и т.н. - оказват огромно влияние върху начина, по който хората общуват помежду си. Нещо повече, в редица страни тези технологии съставляват градивен елемент от цялостната система на обучение и образование.

\section{Медийната грамотност}


Факт е, че за понятието „медийна грамотност” започва да се говори активно почти паралелно с бума в развитието на информационните технологии - в края на втората половина на миналия век. Появява се и придобива смисъл понятието „медиаобразование”, като първоначално (в края на шестдесетте години на 20-ти век) то е свързано само с електронните медии - радио, телевизия и кино.

Ето защо ще разгледаме медийната грамотност в услуга на училището в следните точки:

1.Поставяне на училището в основата на програмата за цифрови технологии и медийна грамотност при институции свързани с образованието;

2.Преподаването в училище в дигиталния 21-ви век;

3.Стимулиране и укрепване, професионалното развитие на учителите.

И тук не може да не споменем приносите на Марк Пренски (Prensky, 2011). Мисията му е да постави учениците в истинския център на образованието. В лекцията си "Образование, чрез което техният свят да стане по-добър. Освобождаване на силата на децата от XXI век" на конференцията "Образование за професиите на бъдещето" (12.04.2017 г., София) той очерта идеите си как днешните ученици трябва да стигнат до бъдещето с развит потенциал и опит вместо със знания от вчерашния свят.

Така националното образование днес предоставя много голям брой данни, свързани с училищния живот, оценки и резултати на учениците, работата и задълженията, които те изпълняват. По този начин голямо разнообразие от лични цифрови и дигитални данни се събират, съхраняват и обработват от множество участници (училища и обучителни центрове, академични служби, местни власти, частни партньори, предоставящи образователни ресурси и цифрови услуги).

Педагогическото взаимодействие в предучилищна и училищна възраст е субектсубектен процес. Това съдейства за поставяне на началото на формирането на медийната грамотност именно в този период, когато децата вече са изложени на отличаващо се с различна интензивност и разнообразие медийно и информационно въздействие. Предполага се, че медиите със своето влияние (предизвикване на любопитство и интерес), медийно съдържание (определен тип информация) и средства, съдействат за изграждането сред децата от предучилищна възраст и първи клас основните компоненти на медийната грамотност. Въпреки нарастващата чувствителност на темата, като пример, 
доклад на Министерството на образованието във Франция, посветен на цифровите и дигитални лични данни, показва, че участниците в образователната общност често не знаят за възможността за повторното им използване, което може да бъде направено от техните дигитални дейности. Разпространението на дигитално оборудване и ресурси, като например разработването на експерименти, използващи потенциала на цифровите технологии, засилва необходимостта от ясна и споделена рамка на доверие между цялата образователна общност.

\section{Дискусия}

Всички изследвания и експерименти, които в момента се провеждат в сектора на дигиталното образование и медийна грамотност в условията на пандемията COVID-19, подчертават основния педагогически потенциал, предлаган от събирането и анализа на училищните данни:

а. преди всичко в полза на ученика, който в крайна сметка ще може да има персонализирана учебна среда, която да му позволи да направи равносметка на силните си страни и нужди, да получи достъп до конкретни педагогически пътеки, да помогне или да направи предложения за дейности или ресурси, съответстващи на нуждите му за напредък и развитие;

б. за учителя, който, освободен от определени времеви дейности, ще може да инвестира това време в педагогическа диференциация благодарение на засилените познания за специфичните нужди на всеки от своите ученици;

в. за изследователи в областта на образованието, които по-добре възприемат и разбират взаимодействията, които насърчават обучението, позволявайки просветлено развитие на практиките;

г. за цялостно управление на образователната система, за статистическо използване на събраните данни за оценка на практиките и за моделиране на бъдещата им еволюция.

Развитието на изкуствения интелект в училищната област ще промени ежедневните практики на учителите, като им помага например да препоръчат съдържание или ресурси или да подпомогне оценяването и коригирането на работата на техните ученици. Той може също така да разкрие нова информация за учебните навици на учениците, като това ще даде възможност на учителите да прилагат учебни ситуации и да подкрепят нуждите на всеки ученик според неговия профил, особено в условията на 
пандемията COVID-19. „Огромните възможности за предлагане на информация, при това по изключително широк крьг от теми, е сериозна предпоставка за нейната либерализация. Този процес засяга пряко формите и начините на комуникация и автоматически рефлектира в учебния процес, поставяйки множество выпросителни пред неговите съдържание и форма. И най-важното - под въпрос е поставен самият краен резултат на обучението, разглеждан през призмата на отношенията между участниците в него. Т.е. под въпрос са поставени методите, чрез които комуникират преподавател и обучаеми, обучаемите помежду си, както и начините, и формите, които се налагат като правила за общуване между тях. Именно разрешаването на този проблем се разглежда като предпоставка за формирането на модерните граждани и общество. За това и теориите за мисията на образованието в модерния свят поставят акцент вече и върху този краен продукт - формирането на отговорни граждани. Цел, за чието осъществяване са нужни съвместни усилия, както от страна на системата, която я налага административната организация на обучението, така и от онези, които пряко я осъществяват, участвайки в нея - обучители и обучаеми. Динамиката на отношенията в този процес показва тенденцията, че обучаемите търсят промените, а преподавателите (или по-голямата част от тях) отстояват наличните правила и норми. Колкото до самата система на администриране на образованието, на различните етапи на развитие тя демонстрира различна степен на приемане на status quo, различно отношение към променящото се равновесие в обучението, движещо се между желанието да се съхранят съществуващите морал и традиция, и стремежа към промени. Казано накратко, тази система остава по-скоро консервативна и йерархично обусловена и по-малко либерална и равностойна” (Bourdieu, 1990, p. 71-107).

Дигиталните технологии позволяват в условията на пандемията COVID-19 да се получи една по-точна оценка, базирана на по-добро оценяване на данните и подобрени възможности за споделяне в образователната общност. Учениците могат да се обучават, самооценяват, да участват в диагностика въз основа на съдържание, адаптирано към тяхното ниво и/или техните нужди. Тези устройства също помагат за освобождаване на учителите от някои досадни задачи за корекция, като им предоставят инструментите, които дават възможност за индивидуализиране на действията им спрямо всеки ученик. Прогресивното разгръщане на свързани обекти във всички области на социалния живот насърчава да поставим тези различни интерактивни и комуникативни продукти в услуга 
на обучението. За Данаил Данов „това е фактор, водещ до създаването на комуникационната компетентност - нагласата към позитивно очакване, осъзнатото желание да се търси и намира ползата, смисъльт от представяната нова информация (познание), любопитството, подтикващо обучаемите да вкусят от това ново познание, и най-вече способността за осмисляне и критичен анализ на наученото, умението за вземане на решение относно това как най-добре предлаганата информация ще е в състояние да улесни и подпомогне личностното развитие. По този начин комуникативната компетентност - знанието, способността и положителното отношение към общуването в процеса на обучение - карат обучаемите да вярват, че успехът на опита им със сигурност ще зависи от степента на неговото усвояване, т.е. от познанието. Зараждането на целият този комплекс от позитивни нагласи, резултат от равноправното третиране на обучаемите, при това от страна на някого, на когото те имат доверие, е найсериозната предпоставка за успеха на обучението" (Danov, 2018, p. 25). Почти всички големи софтуерни фирми обърнаха внимание на едни от най-големите си потребители децата, и разкриха свои отдели за разработка и внедряване на софтуер за обучение сега в условията на пандемията COVID-19. Този софтуер се поднася по различен начин на децата - като компютьрна игра, като обучаваща програма, като web site,и др. Найшироко разпространения софтуер сред децата са компютьрните игри. Те се развиват отпреди 25 години. И в момента те са станали интегрална част от живота на младото поколение. Причините за това са различни. За Марк Пренски тези игри не означават непременно, че децата се обучават в насилие. Всичко зависи от характера на съответните игри. Дава примери с деца, които вече имат постижения в науката, които създават мобилни приложения и имат идеи как да се борят срещу обществени проблеми като тормоза в училище и домашното насилие. Как обаче да запазим и развием вдъхновението им? Немалка част от тези игри не са част от официалната педагогическа култура. Децата ги научават в неформално обкръжение - често те са по-добре подготвени от учителите. Според него съвременният свят прави децата много по-бързо "овластени" - отрано се научават да боравят с различен вид технологии, да развиват практични умения, да имат желанието да усъвършенстват околния свят, да поставят под въпрос правилата около себе си. Казано накратко, М. Пренски смята, че по-скоро ние трябва да ги настигнем, отколкото те нас (Prensky, 2011). Учителите и родителите са част от култура, за която компютрите вече не са нещо ново въпреки, че са интегрална част от тяхното мислене - 
идеята за първите седем години. За тях компютьрните игри са несериозно занимание сериозно е, ако компютрите се използват например за писане на домашни. Изследване в Германия за децата между 6 и 13 години показва, че компютърните игри се налагат като най-интересни (Bauer, 2016). Целта е да се разкрият във връзка с новите медии онези понятия, които се отнасят до "критично потребление на медии", от една страна, или критична "медийна компетентност", от друга. Компенсаторните концепции в практическата медийна педагогика преследват интереса за предаване на знания и умения по такъв начин, че учащите да намерят „връзката““ към (технологичните) разработки, за да компенсират или предотвратят възможни недостатъци. За Т. Байер медийното образование е теоретичен и практически дискурс за медийната култура. Не е случайно, че през учебната 2020 г. като инструмент за подпомагане на учениците в редица страни от ЕС се предлагат дейности за оценка и самопозициониране по всички съответни теми (изучаване на език и четене и писане на съответния език, организация и управление на данни, числа и изчисления, количества и измервания и програмиране по математика). Въз основа на тези резултати се предлагат профилирани дейности за обучение или изграждане на умения у учениците. Благодарение на технологиите за изкуствен интелект в условията на пандемията COVID-19, предложенията, отправени към учениците, са все по-персонализирани и прецизни. Този инструмент се използва независимо от учениците, независимо от оборудването или местоположението на употреба, но и по предложение на учители, в допълнение към работата, изисквана от учениците. Може да позволи редовен мониторинг на обучението от учители.

\section{Заключение}

Поставените въпроси в настоящата статия можем да сведем до следните:,, Как да се предпазим по-добре...?”, „, Как да имаме по-добро оценяване...?”, „Как дигиталните иновации могат да са в услуга на педагогическата ефективност?“, „Има ли и какви са новите инструменти за учителите и учениците?“. Опитахме се да отговорим на някои от тях, което може да има положителен образователен ефект.

\section{Използвана литература}

Danov, D. (2018). Detsata i mediite [The children and the media]. Kliment Ohridski Publishing house.

Bauer, T. (1997). Neue medien und neue pedagogik - Die interoperation von medien und pedagogic. Zur transformation der Medienpedagogik [New media and new pedagogy. 
The interaction of media and pedagogy. On the transformation of media pedagogy] Medien $\bullet$ impulse.

Prensky, M. (2011). H. Sapiens Digital: From digital immigrants and digital natives to digital wisdom. Available from: (accessed January 2011).

$\underline{\text { http://www.innovateonline.info/index.php?view }=\text { article\&id }=705}$ 